\title{
High-temperature Oxidation Behavior of 9Cr Ferritic-steel in Carbon Dioxide
}

\author{
Keitarou KAYA, Shigenari HAYASHI* and Shigeharu UKAI \\ Faculty of Engineering, Hokkaido University, Sapporo, Japan. \\ (Received on October 3, 2013; accepted on January 22, 2014)
}

\begin{abstract}
Commercial STBA26, 9Cr-1Mo ferritic steel, was exposed to $\mathrm{CO}_{2}$ gas and air at $700^{\circ} \mathrm{C}$ in order to understand the oxidation behavior of a $9 \mathrm{Cr}$-steel in $\mathrm{CO}_{2}$ atmosphere. Oxidation of STBA26 was significantly accelerated in $\mathrm{CO}_{2}$ compared to that in air. In $\mathrm{CO}_{2}$ thick iron rich oxide nodules were formed on the steel and chromium rich carbides were found to form below the oxide scale.

The carbon activity at the scale/alloy interface was sufficiently high to maintain parabolic internal continuous carbon supply to the interface is considered to be a reason to cause a breakaway of protective oxide scale.
\end{abstract}

KEY WORDS: high-temperature oxidation; carburization; Carbon dioxide; ferritic steel; oxyfuel combustion.

\section{Introduction}

Low-chromium ferritic steels are widely used for heat exchangers in power plants, with metal surface temperature up to about $600^{\circ} \mathrm{C}$, due to their good high temperature mechanical properties and acceptable oxidation resistance. ${ }^{1)}$ Recently Carbon dioxide Capture and Storage, CCS, technologies are being considered in order to remove carbon dioxide from the emission gas of fossil-fuel power plants. The oxyfuel combustion process in coal-power plants is one of the CCS technologies. Under oxyfuel combustion, oxygen is used instead of air, and the resulting $\mathrm{CO}_{2}$ concentration in the exhaust gas is expected to be much higher than that from the airfuel combustion process. ${ }^{2,3)}$ Therefore it is important to examine the high temperature oxidation behavior of ferritic steels in high $\mathrm{CO}_{2}$ atmospheres in order to evaluate the capability of low-Cr steels in oxyfuel combustion plants.

Several studies related to the oxidation of $\mathrm{Fe}-\mathrm{Cr}$ alloy in $\mathrm{CO}_{2}$-based environments have been reported. ${ }^{4-11)}$ All of these studies reported that $\mathrm{Fe}-\mathrm{low} \mathrm{Cr}$ alloys oxidized significantly in $\mathrm{CO}_{2}$-enriched atmospheres with formation of a thick duplex Fe-rich oxide scale accompanied by internal Cr-rich carbides, and suggested that higher $\mathrm{Cr}$ content is required in order to form a protective $\mathrm{Cr}_{2} \mathrm{O}_{3}$ scale. ${ }^{4)}$ The thick duplex oxide scale formed in $\mathrm{CO}_{2}$-enriched atmospheres usually consists of the outer Fe-oxide and inner Fe-Cr-spinel oxide layers, and contains a lot of voids and cavities. The growth mechanism of such a duplex oxide scale in $\mathrm{CO}_{2}$-enriched atmospheres during the steady-state oxidation stage have been also well discussed, and was considered to be essentially same as the oxidation in $\mathrm{H}_{2} \mathrm{O}$ containing atmosphere; the outer Fe-rich oxide and inner

* Corresponding author: E-mail: hayashi@eng.hokudai.ac.jp DOI: http://dx.doi.org/10.2355/isijinternational.54.1379
$\mathrm{Fe}-\mathrm{Cr}$ spinel oxide layers grow by outward iron and inward oxygen diffusion, respectively. For example, Fujii et al. ${ }^{6}$ proposed the generation of a $\mathrm{CO}_{2}-\mathrm{CO}$ atmosphere within the voids in the porous scale, and these are the carriers for oxygen and carbon, which are the oxidants for formation and growth the inner layer, through the oxide scale via void channels to the alloy surface. Similar mechanism was also proposed by Rouillard et al. ${ }^{8,9)}$ from their study using Fe9Cr-1Mo alloy (T91) oxidized in $\mathrm{CO}_{2}$ at $550^{\circ} \mathrm{C}$.

Although much attention has been paid for the growth mechanism of duplex scale in $\mathrm{CO}_{2}$-enriched atmospheres, the influence of $\mathrm{CO}_{2}$ and/or carbon for the initiation of such a thick oxide scale formation, i.e., the breakaway of protective $\mathrm{Cr}_{2} \mathrm{O}_{3}$ scale, is yet to be well understood. Detrimental effect of $\mathrm{CO}_{2}$ was often considered to be due to the internal precipitation of $\mathrm{Cr}$-rich carbides, which consume $\mathrm{Cr}$ in the subsurface region and prevent $\mathrm{Cr}$ supply to maintain the protective $\mathrm{Cr}_{2} \mathrm{O}_{3}$ scale. With this model, carbon must diffuse inwardly via $\mathrm{Cr}_{2} \mathrm{O}_{3}$ scale; however, the paths for carbon diffusion and the diffusion species such as molecule $\mathrm{CO}_{2}$, atomic carbon, etc. are still being open discussion. Recent study by Gheno et al. ${ }^{11)}$ suggested that the carburization beneath the oxide scale is a consequence of the formation of Fe-rich oxide nodules, and not a cause the breakaway of $\mathrm{Cr}_{2} \mathrm{O}_{3}$ scale. They also proposed that carbon entry into the $\mathrm{Cr}_{2} \mathrm{O}_{3}$ scale along the grain boundaries causes the faster grain boundary diffusion and poor scale mechanical properties, which may affect detrimentally for maintaining the protective $\mathrm{Cr}_{2} \mathrm{O}_{3}$ scale.

This paper is one of the series of oxidation studies of Felow $\mathrm{Cr}$ alloy in $\mathrm{CO}_{2}$-enriched atmospheres. The aim of these studies is to elucidate the mechanism of carbon entry into the protective $\mathrm{Cr}_{2} \mathrm{O}_{3}$ scale, which could cause a breakaway of protective $\mathrm{Cr}_{2} \mathrm{O}_{3}$ scale. In the present paper, we investigated a short-term oxidation behavior of Fe-9Cr-1Mo ferritic 
steel in $\mathrm{CO}_{2}$, and the formation behavior of Fe-rich oxide scale in $\mathrm{CO}_{2}$ was investigated. In order to accelerate the breakaway of protective $\mathrm{Cr}_{2} \mathrm{O}_{3}$ scale, oxidation experiment was conducted at $700^{\circ} \mathrm{C}$ in this study.

\section{Experimental Procedures}

Samples $15 \times 7 \times 2 \mathrm{~mm}^{3}$ in size were cut from a commercial STBA26 boiler tube and ground to a 2400-grit finish using $\mathrm{SiC}$ abrasion paper. The sample surfaces were then polished with $3 \mu \mathrm{m}$ diamond paste, followed by ultrasonic cleaning in acetone prior to oxidation testing. The composition of STBA26 used in the present study is shown in Table 1. Figure 1 shows a schematic illustration of equipment used for the oxidation tests in $\mathrm{CO}_{2}$ gas. The test specimens were set in the furnace hot zone by suspending them in an alumina crucible on top of an alumina tube. The air oxidation tests were conducted in a box furnace in laboratory air.

Samples were oxidized at $700^{\circ} \mathrm{C}$ in flowing $\mathrm{CO}_{2}$ gas with a flow rate of $150 \mathrm{~cm}^{3} / \mathrm{min}(3.9 \mathrm{~cm} / \mathrm{min})$, for up to $100 \mathrm{~h}$. The atmosphere of the reaction tube was replaced with $\mathrm{CO}_{2}$ gas prior to each oxidation test in $\mathrm{CO}_{2}$. The samples were heated at a rate of $10^{\circ} \mathrm{C} / \mathrm{min}$ to the oxidation temperature of $700^{\circ} \mathrm{C}$ in a flowing $\mathrm{CO}_{2}$ gas stream with a flow rate of 150 $\mathrm{cm}^{3} / \mathrm{min}$. After the oxidation test, the samples were furnace cooled in a $\mathrm{CO}_{2}$ gas stream with a flow rate of $50 \mathrm{~cm}^{3} / \mathrm{min}$ $(1.3 \mathrm{~cm} / \mathrm{min})$.

Reaction mass gain was obtained by measuring the sample weight before and after exposure to a given oxidation time using a precision balance. The surface and cross-sectional microstructures of the samples were examined by scanning electron microscopy (SEM), optical microscopy (OM) and transmission electron microscopy (TEM). Murakami's reagent, which contains $1.78 \mathrm{~mol} \mathrm{KOH}$ and $0.304 \mathrm{~mol} \mathrm{~K}_{3}\left[\mathrm{Fe}(\mathrm{CN})_{6}\right]$ per liter, was used for etching the

Table 1. Composition of STBA26 (in wt.\%).

\begin{tabular}{ccccccc}
\hline $\mathrm{C}$ & $\mathrm{Si}$ & $\mathrm{Mn}$ & $\mathrm{P}$ & $\mathrm{S}$ & $\mathrm{Cr}$ & $\mathrm{Mo}$ \\
\hline 0.12 & 0.45 & 0.42 & 0.013 & 0.003 & 8.6 & 0.93 \\
\hline
\end{tabular}

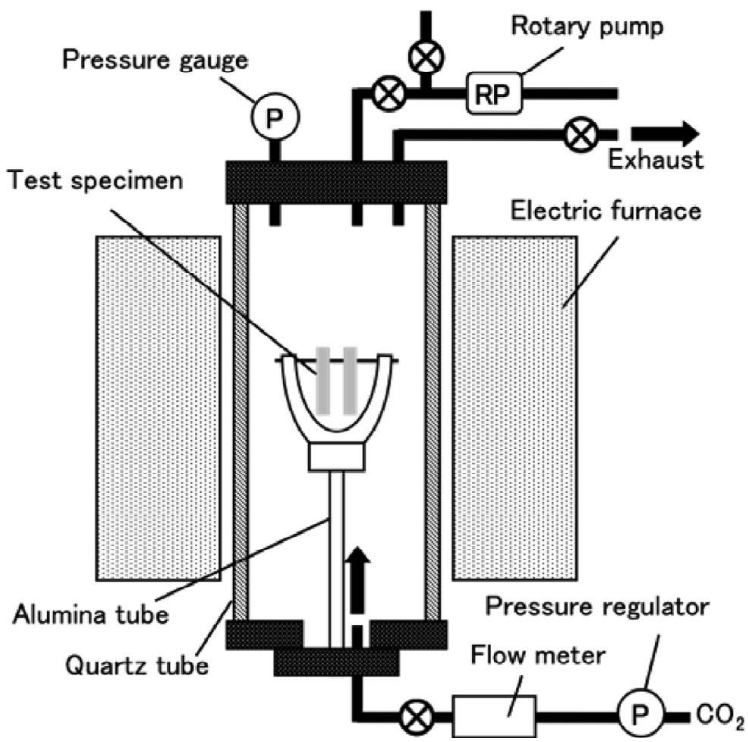

Fig. 1. Schematic illustration of the equipment used in this study. cross-sections. Some of specimens were analyzed by electron probe micro-analyzer (EPMA) and energy dispersive X-ray spectroscopy (EDS) to determine the distribution of each element and identify the structures of the reaction products.

\section{Results}

\subsection{Kinetics of Oxidation}

Figure 2 shows the oxidation kinetics of STBA26 in $\mathrm{CO}_{2}$ and air at $700^{\circ} \mathrm{C}$. Samples were oxidized very slowly in air and the oxidation kinetics showed parabolic behavior. How-

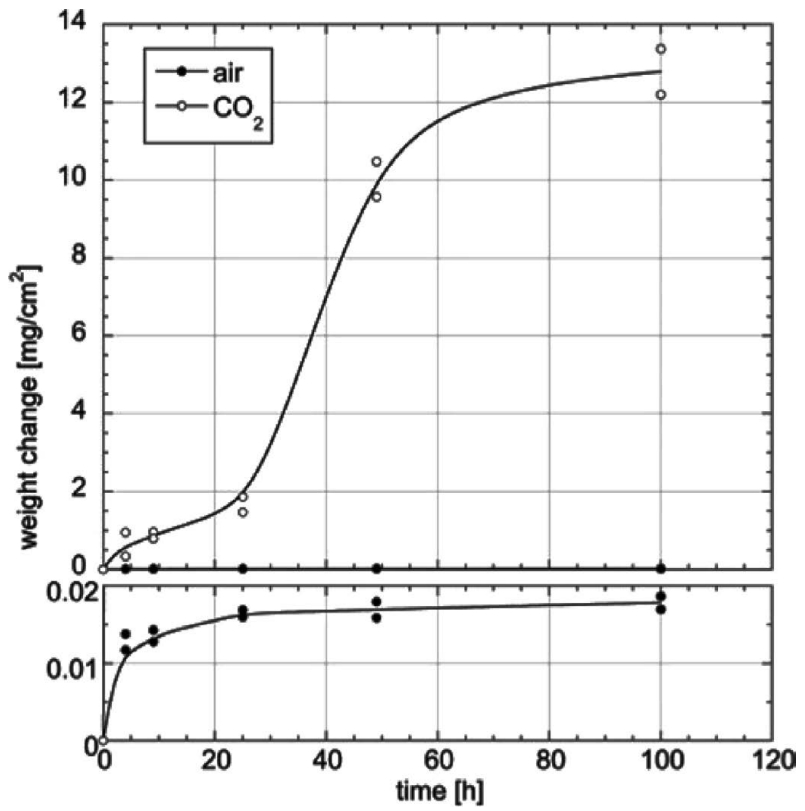

Fig. 2. Oxidation kinetics of STBA26 at $700^{\circ} \mathrm{C}$.
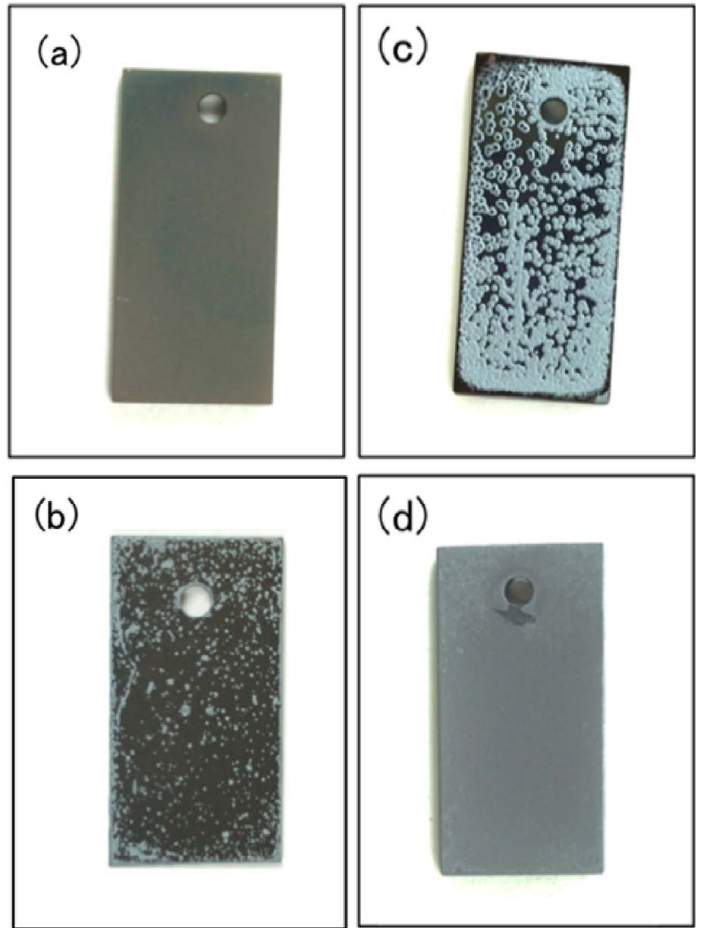

(d)

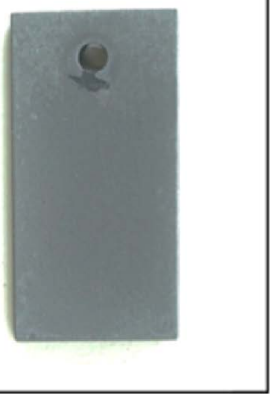

Fig. 3. Surface appearance of specimens after (a) $100 \mathrm{~h}$ oxidation in air and (b) $4 \mathrm{~h}$, (c) $25 \mathrm{~h}$, (d) $100 \mathrm{~h}$ in $\mathrm{CO}_{2}$ at $700^{\circ} \mathrm{C}$. (Online version in color.) 

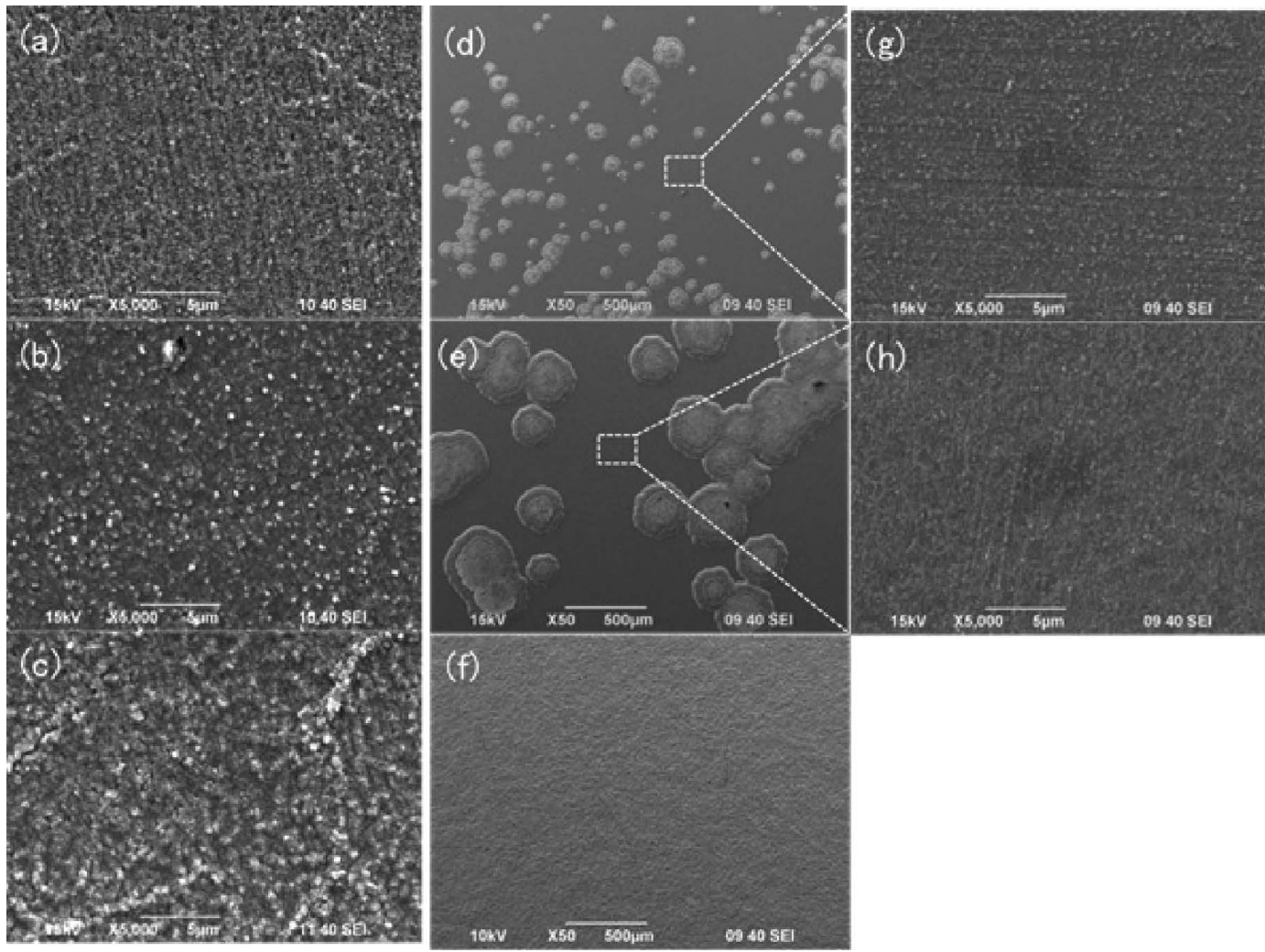

Fig. 4. Surface morphologies of STBA26 after (a) $4 \mathrm{~h}$, (b) $25 \mathrm{~h}$, (c) $100 \mathrm{~h}$ of oxidation in air and (d) (g) $4 \mathrm{~h}$, (e) (h) $25 \mathrm{~h}$, (f) $100 \mathrm{~h}$ of oxidation in $\mathrm{CO}_{2}$ at $700^{\circ} \mathrm{C}$.

ever in $\mathrm{CO}_{2}$ the samples were initially oxidized at a faster rate, and the rate of oxidation was further increased rapidly after about $25 \mathrm{~h}$ of oxidation.

\subsection{Surface Morphology and Cross-sectional Micro- structure}

Figure 3 shows the surface appearance of samples after oxidation tests in air and $\mathrm{CO}_{2}$, at $700^{\circ} \mathrm{C}$ for 4,25 and 100 $\mathrm{h}$. The surface of the specimens oxidized in air for $100 \mathrm{~h}$ was smooth and showed interference color, which indicates that the thickness of oxide scales were very thin. On the surface of the samples oxidized in $\mathrm{CO}_{2}$ for 4 and $25 \mathrm{~h}$ many oxide nodules were formed, but other areas where nodules were not formed were similar to the surfaces formed in air. After $100 \mathrm{~h}$ of oxidation in $\mathrm{CO}_{2}$, the nodules had grown laterally and covered the entire surface by a thick oxide scale. Figure 4 shows the surface morphologies of the oxides formed in air and $\mathrm{CO}_{2}$ at $700^{\circ} \mathrm{C}$. In air the surface was covered by small granular reaction products, and those grew larger with oxidation time. In $\mathrm{CO}_{2}$ a large number of nodules with varied sizes were formed after $4 \mathrm{~h}$ of oxidation, and they grew larger in size after $25 \mathrm{~h}$ of oxidation. After $100 \mathrm{~h}$, the surface was completely covered by thick oxide scale due to lateral growth of the nodules. Similar oxidation products to that formed in air were observed in the areas without nodule formation.

Figure 5 shows TEM cross-sections from areas where thin oxide scales were developed after $25 \mathrm{~h}$ in air and after 4 and $25 \mathrm{~h}$ in $\mathrm{CO}_{2}$. Thin chromium rich oxide scales were developed all samples, and $\mathrm{Cr}_{2} \mathrm{O}_{3}$ scale developed in $\mathrm{CO}_{2}$ grew thicker with time. Although $\mathrm{Cr}_{2} \mathrm{O}_{3}$ scale formed in $\mathrm{CO}_{2}$ was thinner than that in air after $25 \mathrm{~h}$ of oxidation, no apparent microstructural difference was observed. Figure 6
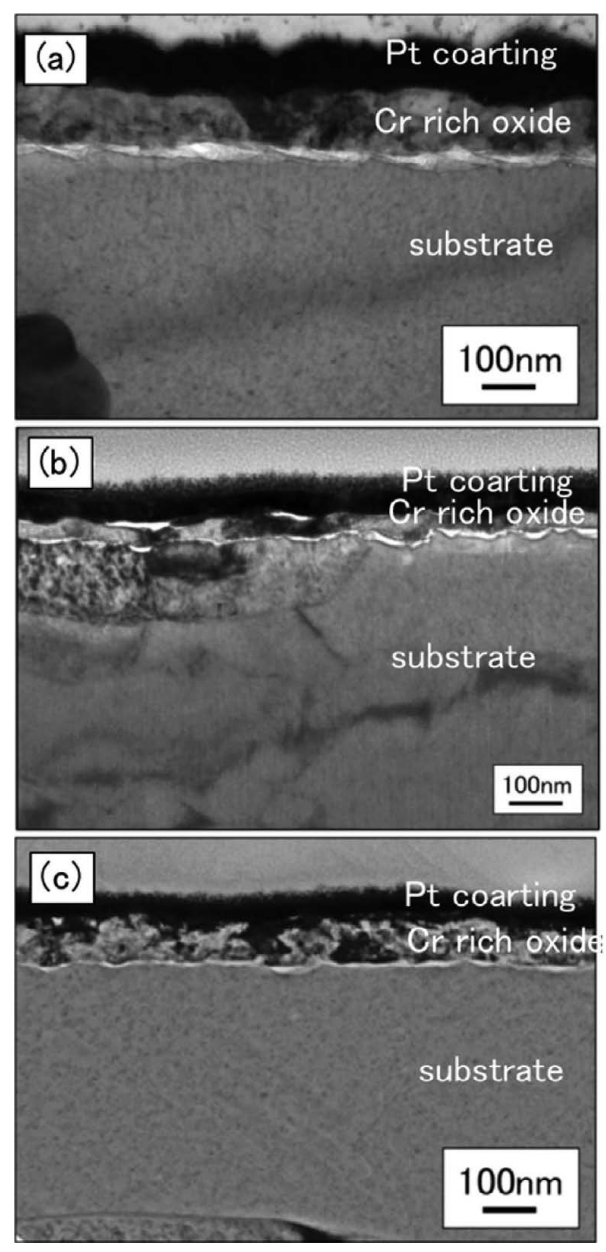

Fig. 5. Cross-sectional microstructure of STBA26 after (a) $25 \mathrm{~h}$ of oxidation in air and (b) $4 \mathrm{~h}$, (c) $25 \mathrm{~h}$ in $\mathrm{CO}_{2}$ at $700^{\circ} \mathrm{C}$. 
shows cross-sections of the oxide scale formed in $\mathrm{CO}_{2}$ at different oxidation times. The oxide nodules consisted of a duplex structure with outer $\mathrm{Fe}_{3} \mathrm{O}_{4}$ and inner $\mathrm{Fe}-\mathrm{Cr}$ oxide layers. Both outer and inner layers became thicker with time, and internal oxide precipitates were observed below the inner layer.

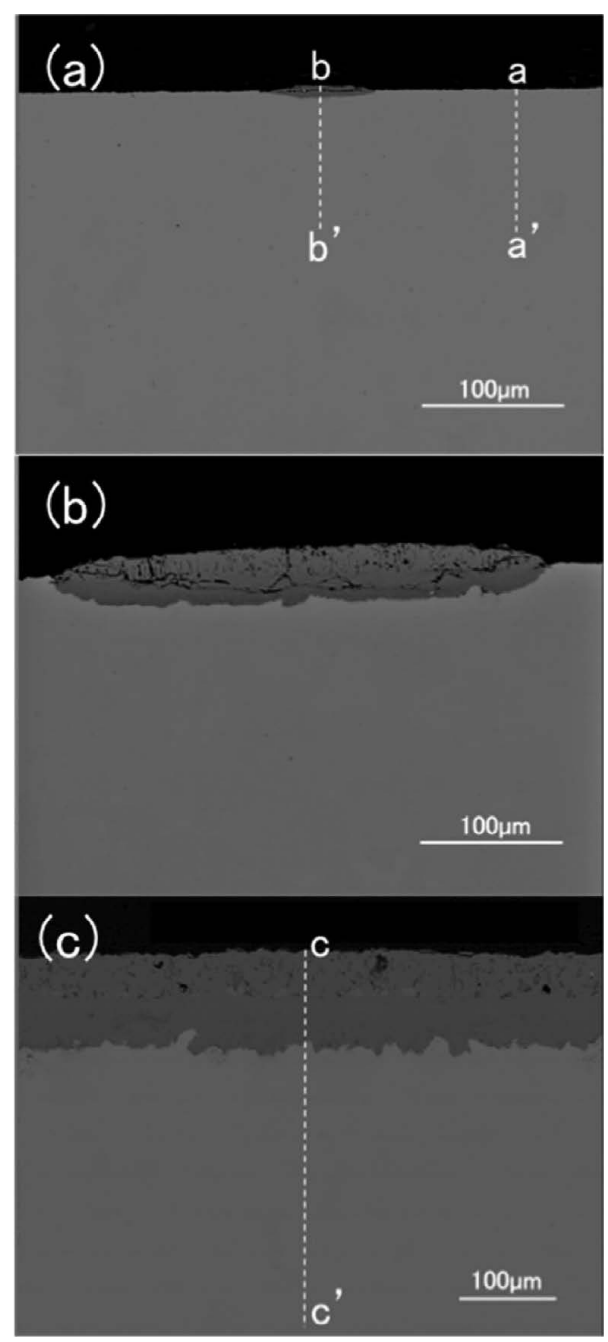

Fig. 6. Cross-sectional microstructure of STBA26 after (a) $4 \mathrm{~h}$, (b) $25 \mathrm{~h}$, (c) $100 \mathrm{~h}$ of oxidation in $\mathrm{CO}_{2}$ at $700^{\circ} \mathrm{C}$.

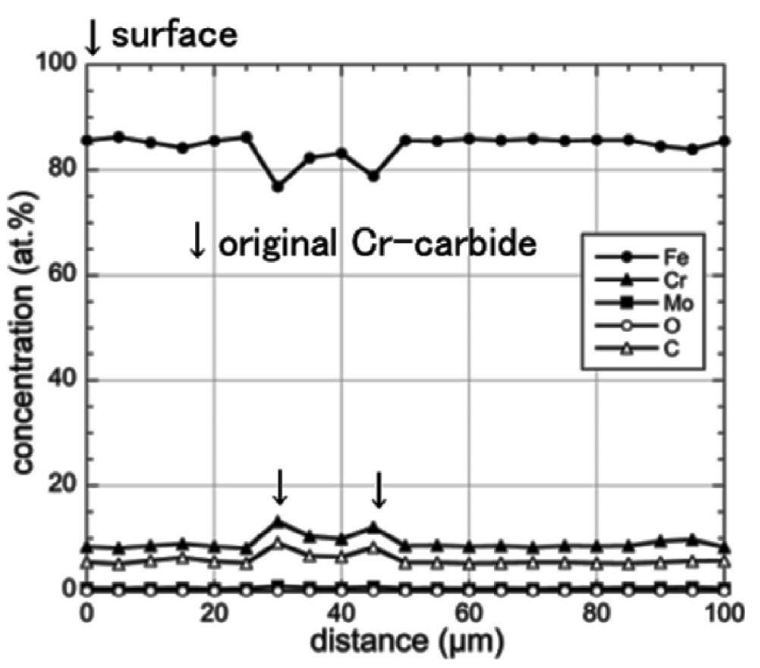

Fig. 7. Concentration profiles of each element of STBA26 after $4 \mathrm{~h}$ of oxidation in air at $700^{\circ} \mathrm{C}$.
Figures 7, 8 shows the results of EPMA analysis of the samples after $4 \mathrm{~h}$ of oxidation in air and $\mathrm{CO}_{2}$ and $100 \mathrm{~h}$ of oxidation in $\mathrm{CO}_{2}$. Original chromium carbide precipitates were detected in the alloy substrates in air and in $\mathrm{CO}_{2}$ after $4 \mathrm{~h}$ (See allows in Figs. 7, 8(a) 8(b)). Cr depletion toward the scale/alloy interface was observed at the area, where $\mathrm{Cr}_{2} \mathrm{O}_{3}$ was developed on the both samples, but no apparent difference of distribution of each element in the subsurface region was observed in the samples oxidized in both atmospheres. However after $100 \mathrm{~h}$ of oxidation in $\mathrm{CO}_{2}$, chromium-rich carbide formation was observed in the subsurface
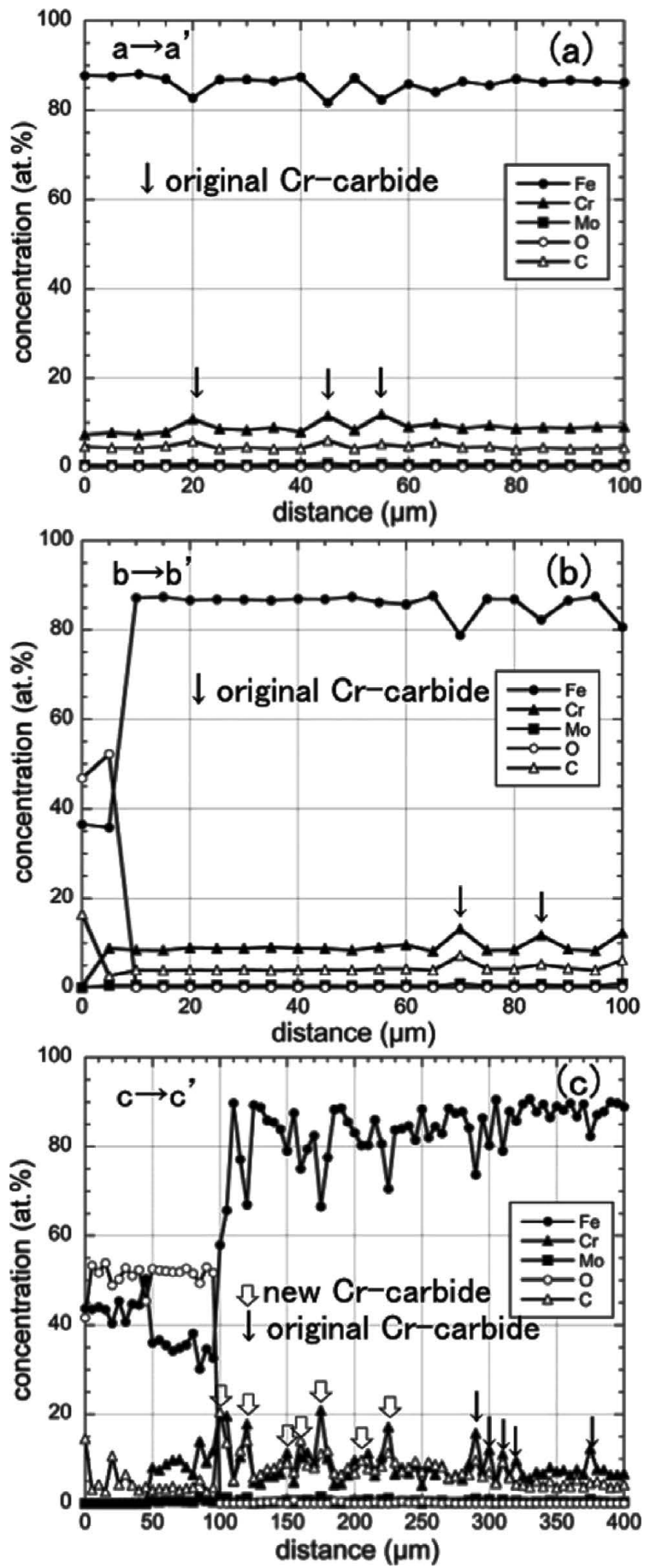

Fig. 8. Cross-sectional concentration profiles of each element of STBA26 after oxidation in $\mathrm{CO}_{2}$; (a) $4 \mathrm{~h}$, no oxide nodule region, (b) $4 \mathrm{~h}$, oxide nodule, (c) $100 \mathrm{~h}$, analysis was conducted along the lines in Fig. 6. 
region of the sample. $\mathrm{Cr}$ content in this subsurface region decreased to around 3 at.\%.

\subsection{Internal Carburization}

Figure 9 shows etched cross-sections of the samples after 25, 49 and $100 \mathrm{~h}$ of oxidation in $\mathrm{CO}_{2}$. The network-like internal chromium carbide zone was formed below Fe-rich nodules and grew inward with time. Figure 10 shows the growth kinetics of the internal carburization zone. The linear

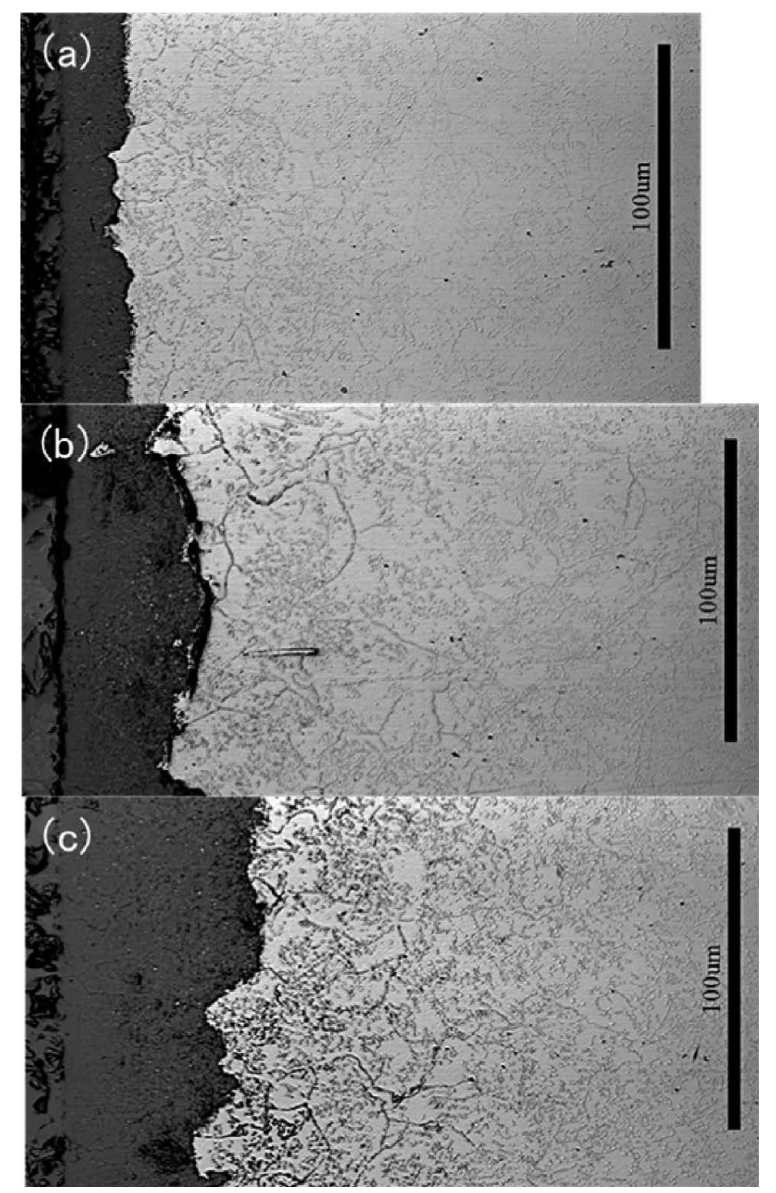

Fig. 9. Etched cross-sectional microstructure of the specimens of STBA26 after (a) $25 \mathrm{~h}$, (b) $49 \mathrm{~h}$, (c) $100 \mathrm{~h}$ of oxidation in $\mathrm{CO}_{2}$ at $700^{\circ} \mathrm{C}$.

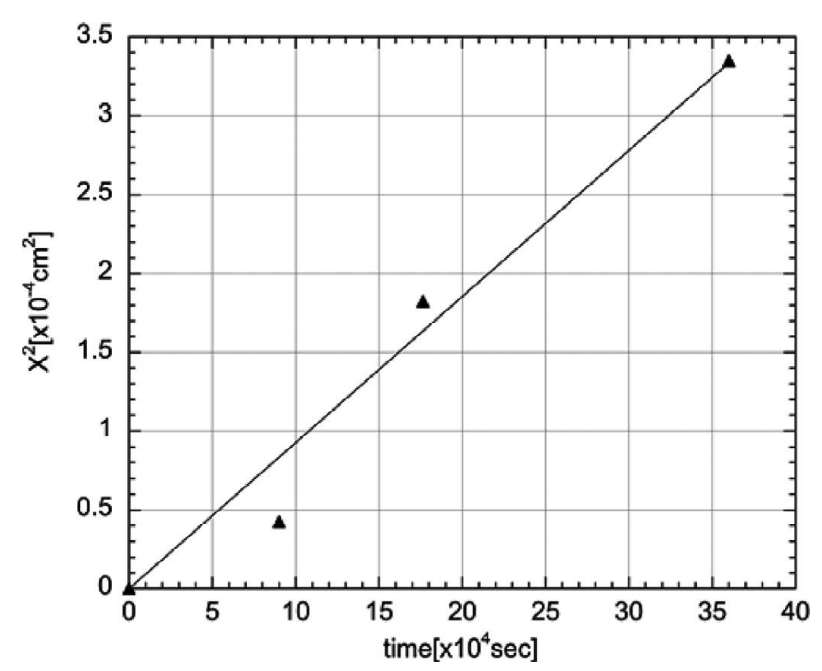

Fig. 10. Precipitation depth of the carbide layer of STBA26 after oxidation in $\mathrm{CO}_{2}$ at $700^{\circ} \mathrm{C}$. relationship between thickness of the internal carburization zone and the square root of oxidation time indicates that the growth of internal carburization zone followed parabolic kinetics. The parabolic rate constant obtained from Fig. 10 was $4.6 \times 10^{-10} \mathrm{~cm}^{2} / \mathrm{sec}$.

\section{Discussion}

\subsection{Internal Carburization}

Fe-9Cr-1Mo steel oxidized slowly in air due to formation of $\mathrm{Cr}$-rich protective oxide scale. The oxidation rate was much faster in $\mathrm{CO}_{2}$ due to formation of Fe-rich oxide nodules, which grew larger in size with oxidation time. An internal carburization zone was only found to occur below the oxide nodules and grew thicker with time.

Since the $\mathrm{CO}_{2}$ gas $(>99.5 \%)$ used in this study contained impurity oxygen, the $\mathrm{C}, \mathrm{O}_{2}, \mathrm{CO}$ and $\mathrm{CO}_{2}$ in the atmosphere are considered to equilibrate at $700^{\circ} \mathrm{C}$ by following the reactions:

$$
\begin{gathered}
\mathrm{CO}_{2}=\mathrm{CO}+\frac{1}{2} \mathrm{O}_{2} \\
2 \mathrm{CO}=\mathrm{CO}_{2}+\mathrm{C} .
\end{gathered}
$$

Under the assumption of $P_{\mathrm{O}_{2}}=1 \times 10^{-6}$ atm from impurity oxygen, the equilibrium oxygen partial pressure and the carbon activity in the $\mathrm{CO}_{2}$ gas at $700^{\circ} \mathrm{C}$ in $P_{\text {Total }}=1$ atm were calculated to be $P_{\mathrm{O}_{2}}=5.8 \times 10^{-6}$ atm and $a_{\mathrm{C}}=9.5 \times 10^{-15}$, respectively. Carbon can penetrate into an alloy substrate if carbon activity in the alloy is lower than that in the atmosphere, and may form internal carbides. The calculated carbon activity in $\alpha$-phase of the alloy calculated by ThermoCalc software is $a_{\mathrm{C}}=0.0015$. This carbon activity is much greater than that of the $\mathrm{CO}_{2}$ atmosphere. Therefore penetration of $\mathrm{C}$ into the alloy substrate will not occur.

With the Cr activity in the alloy $a_{\mathrm{Cr}}=0.408$, the most stable carbide is $\mathrm{Cr}_{7} \mathrm{C}_{3}$. This carbide forms by reaction (3):

$$
\frac{7}{3} \mathrm{Cr}+\mathrm{C}=\frac{1}{3} \mathrm{Cr}_{7} \mathrm{C}_{3}
$$

The Gibbs free energy change of carbide formation expressed by reaction (3) can be described as:

$$
\Delta G(3)=\Delta G^{0}(3)+R T \ln \left(a_{C_{7} C_{3}}^{1 / 3} / a_{C r}^{7 / 3} a_{C}\right)
$$

where $R$ is the gas constant and $T$ is temperature in Kelvin. At $700^{\circ} \mathrm{C}$, the calculated $\Delta G$ of reaction (3), with the carbon activity in the $\mathrm{CO}_{2}$ atmosphere, $a_{\mathrm{C}}=9.5 \times 10^{-15}$, is $\Delta G(3)=$ $221 \mathrm{~kJ} / \mathrm{mol}$ where chromium activity in the alloy was $0.408,{ }^{12)}$ and the chromium carbide activities were 1 . Therefore chromium carbides could not be formed on the alloy surface in $\mathrm{CO}_{2}$ at $700^{\circ} \mathrm{C}$.

The reaction of chromium oxide formation is described as:

$$
\frac{4}{3} \mathrm{Cr}+\mathrm{O}_{2}=\frac{2}{3} \mathrm{Cr}_{2} \mathrm{O}_{3}
$$

The Gibbs free energy change of reaction (4) is:

$$
\Delta G(4)=\Delta G^{0}(4)+R T \ln \left(a_{\mathrm{Cr}_{2} \mathrm{O}_{3}}^{2 / 3} / a_{C r}^{4 / 3} P_{\mathrm{O}_{2}}\right)
$$

Using the oxygen partial pressure in $\mathrm{CO}_{2}$ calculated above, $P_{\mathrm{O}_{2}}=5.8 \times 10^{-6} \mathrm{~atm}$, the Gibbs free energy change of chromium oxide formation at $700^{\circ} \mathrm{C}$ is $-482 \mathrm{~kJ} / \mathrm{mol}$, therefore 
chromium oxide scale can be formed in $\mathrm{CO}_{2}$. Indeed the formation of a thin chromium oxide scale was observed after oxidation in $\mathrm{CO}_{2}$, as shown Fig. 5.

When chromium oxide scale is formed on the alloy surface, the oxygen potential decreases across the oxide scale toward the scale/alloy interface. The estimated partial pressure of oxygen at the scale/alloy interface was calculated to be $P_{\mathrm{O}_{2}}=7.4 \times 10^{-32} \mathrm{~atm}$.

From reaction (1), the $P_{\mathrm{CO}} / P_{\mathrm{CO}_{2}}$ ratio can be expressed by the following equation:

$$
\left(P_{\mathrm{CO}} / P_{\mathrm{CO}_{2}}\right)=K_{(1)}\left(P_{\mathrm{O}_{2}}^{-1 / 2}\right)
$$

where $K_{(1)}$ is the equilibrium constant of reaction (1). Under the assumption that $\mathrm{CO}_{2}$ can penetrate chromium oxide scale, the $P_{\mathrm{CO}} / P_{\mathrm{CO}_{2}}$ ratio at the scale/alloy interface increases due to the decrease in oxygen potential, resulting in an increase in carbon activity in accordance with and Eqs. (6) and (7).

$$
\left(P_{\mathrm{CO}_{2}} / P_{\mathrm{CO}}^{2}\right)=K_{(2)}\left(a_{\mathrm{C}}^{-1}\right)
$$

With the total pressure at the interface, $P_{\mathrm{T}}$, described by following equation,

$$
P_{\mathrm{T}}=P_{\mathrm{CO}_{2}}+P_{\mathrm{CO}}+P_{\mathrm{O}_{2}}
$$

Eq. (6) can be rewritten as Eq. (7), ${ }^{11)}$ omitting small $P_{\mathrm{O}_{2}}$

$$
a_{\mathrm{C}}=K_{(2)} \frac{\left(P_{\mathrm{CO}} / P_{\mathrm{CO}_{2}}\right)^{2} P_{\mathrm{T}}}{1+\left(P_{\mathrm{CO}} / P_{\mathrm{CO}_{2}}\right)}
$$

This increase in carbon activity at the interface resulted in the formation of internal carbides.

Changes in oxygen partial pressure and carbon activity above mention are schematically illustrated in Figs. 11 and 12. In $\mathrm{CO}_{2}$ atmosphere $\mathrm{Cr}_{2} \mathrm{O}_{3}$ phase is stable as shown a black circle as Fig. 11, and carbon activity increases by Eqs. (5)-(7) as oxygen potential decreases in $\mathrm{Cr}_{2} \mathrm{O}_{3}$ scale toward the oxide/alloy interface. Finally $\mathrm{Cr}_{7} \mathrm{C}_{3}$ phase becomes stable below the $\mathrm{Cr}_{2} \mathrm{O}_{3}$ scale.

\subsection{Carburization Kinetics}

In this study parabolic growth of the internal carburization zone was observed (Fig. 10). The depth of the internal carburization zone, ICZ, $X$ is expressed by Eq. (8) as a function of oxidation time.

$$
X^{2}=2 k_{\mathrm{p}} t
$$

The carbon permeability, $N_{\mathrm{C}}^{(\mathrm{S})} D_{\mathrm{C}}$, is expected to be much greater than that of chromium, $N_{\mathrm{C}}{ }^{(\mathrm{S})} D_{\mathrm{C}}>N_{\mathrm{Cr}}{ }^{(0)} D_{\mathrm{Cr}},{ }^{14)}$ therefore the rate constant of internal carburization, $k_{\mathrm{p}}$ can be expressed as: $:^{13,14)}$

$$
k_{\mathrm{p}}=\frac{N_{\mathrm{C}}^{(s)} D_{\mathrm{C}}}{v N_{\mathrm{Cr}}^{(0)}}
$$

Here, $N_{\mathrm{C}}{ }^{(\mathrm{S})}$ and $N_{\mathrm{Cr}}{ }^{(0)}$ are mole fractions, and $D_{\mathrm{C}}$ and $D_{\mathrm{Cr}}$ are diffusion coefficients of solute carbon and $\mathrm{Cr}$, respectively, and $v$ is the stoichiometric ratio of the carbide (C per atom of metal). The $k_{\mathrm{p}}$ obtained in this study from Fig. 10 was $4.6 \times$ $10^{-10} \mathrm{~cm}^{2} \mathrm{sec}^{-1} . N_{\mathrm{C}}{ }^{(\mathrm{S})}$ in the alloy can be calculated by Eq. (9) using the parabolic rate constant, $k_{\mathrm{p}}$, initial alloy $\mathrm{Cr}$ content, $N_{\mathrm{Cr}}=0.09, \mathrm{C}$ diffusion coefficient in $\alpha$-Fe, $D_{\mathrm{C}}=0.6 \times 10^{-6}$ $\left.\mathrm{cm}^{2} \mathrm{sec}^{-1},{ }^{15}\right)$ and the stoichiometric factor of $\mathrm{M}_{7} \mathrm{C}_{3}, v=$ 0.429 . The calculated $N_{\mathrm{C}}{ }^{(\mathrm{S})}$ was $3.0 \times 10^{-5}$, and the carbon

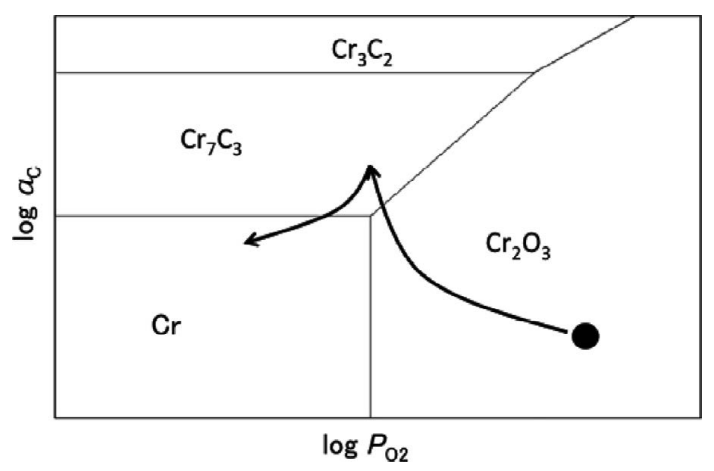

Fig. 11. Schematic of stability diagram for the $\mathrm{Cr}-\mathrm{O}-\mathrm{C}$ system at $700^{\circ} \mathrm{C}$.

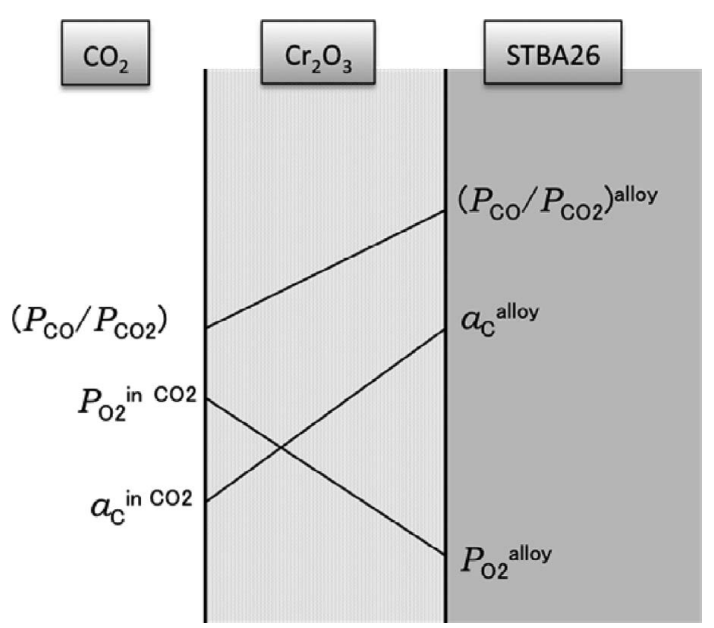

Fig. 12. Schematic of the carbon activity in during oxidation in $\mathrm{CO}_{2}$.

activity at the alloy surface was obtained to be $a_{\mathrm{C}}=0.049$. This carbon activity is sufficient to form chromium carbides in alloy substrate, and therefore formation of carbide below the protective Cr-rich oxide scale is likely to be one of reasons to cause breakaway of the protective oxide scale.

\subsection{The Effect of Carbon Dioxide on Alloy Oxidation}

As shown in Fig. 2, samples were significantly oxidized in $\mathrm{CO}_{2}$ at $700^{\circ} \mathrm{C}$ by formation of a thick iron-rich oxide (Figs. 6, 8). Although no carbides formation was observed after $4 \mathrm{~h}$ of oxidation (See Figs. 6(a) and 8(a) 8(b)), chromium carbides were observed at the alloy surface (see Fig. 9) below the Fe-rich oxide scale after $25 \mathrm{~h}$ of oxidation, and a $\mathrm{Cr}$ depleted zone was developed in the subsurface region. The formation of this $\mathrm{Cr}$ depleted zone in the alloy is being unable to maintain a protective chromium oxide scale. Therefore oxidation transitioned from protective $\mathrm{Cr}$-rich oxide scale to less protective iron-rich oxide formation. The reason for no carbide observation below iron-rich nodules after a shorter time exposure could be faster inward growth of nodules. Thin carburization zone formed initially was rapidly consumed and incorporated in the inner layer by inward growth of iron-nodules.

Iron-rich oxide nodules were first observed after $4 \mathrm{~h}$ of oxidation in $\mathrm{CO}_{2}$ and grew larger with time, however the number of nodules stayed almost constant with oxidation time. This behavior indicates that there are intrinsic defects in the initially formed protective oxide scale, and nodules 


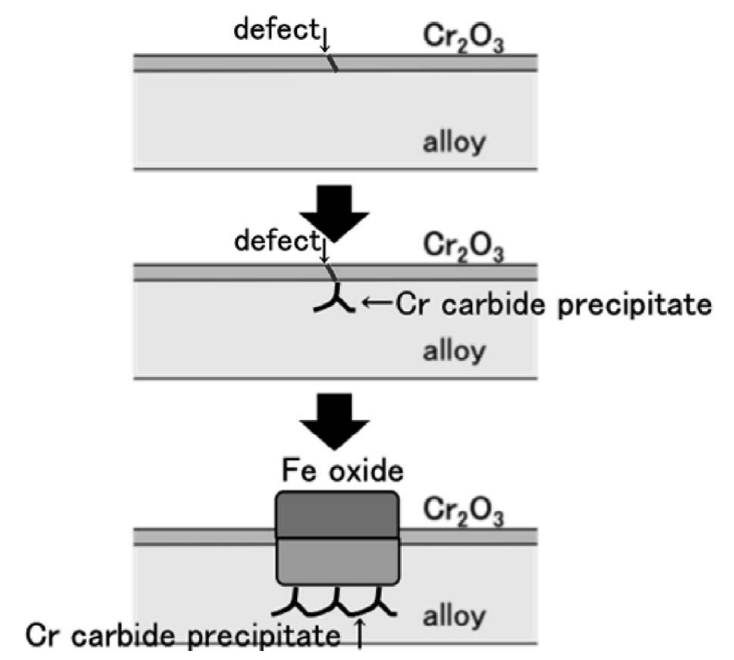

Fig. 13. Schematic of a development of nodules oxidized in $\mathrm{CO}_{2}$.

may form at those defects by carbon penetration as shown in Fig. 13. Wolf et al. ${ }^{10)}$ also suggested that the continuous and dense $\mathrm{Cr}_{2} \mathrm{O}_{3}$ scale could inhibit the carbon penetration, but carbon transport could occur through pores or microchannels in $\mathrm{Cr}_{2} \mathrm{O}_{3}$ scale which were induced by impurities on surface of alloy before oxidation. The presence of defects, which allow the carbon penetration into the scale/ alloy interface is likely, however, defects in the Cr-rich scale could not be observed by TEM observation in the present study. Further investigation is required to confirm the defects in protective oxide scale.

\section{Summary}

In this study the oxidation behavior of $\mathrm{Fe}-9 \mathrm{Cr}$ steel, STBA26, in $\mathrm{CO}_{2}$ gas at $700^{\circ} \mathrm{C}$ was examined. The results may be summarized as follows:
1. STBA26 displayed excellent oxidation resistance in air at $700^{\circ} \mathrm{C}$, however it was oxidized heavily in $\mathrm{CO}_{2}$.

2. An acceleration in oxidation rate was caused by chromium depletion in the surface region due to formation of internal carbides in STBA26 in $\mathrm{CO}_{2}$.

3. Formation of internal carbide can be explained by an increase in carbon activity at the scale/alloy interface, due to decrease in $\mathrm{PO}_{2}$ after formation of chromium-rich oxide scale on the alloy surface.

\section{Acknowledgements}

The authors gratefully acknowledge financial support provided by the Iron and Steel Institute of Japan through a Research Promotion Grant.

\section{REFERENCES}

1) S. Nakamori, N. Otsuka, M. Kyo, Y. Nakajima, S. Hayashi, Y. Fukuda and A. Motoi: High Temperature Corrosion and Prevention Methods by Combustion Gas in Boiler, Technosystem Co., Tokyo, (2012), 12.

2) A. Kather and S. Kownatzki: Int. J. Greenhouse Gas Cont., 5S (2011), S204.

3) K.-D. Tigges, F. Klauke, C. Bergins, K. Busekrus, J. Niesbach, M. Ehmann, C. Kuhr, F. Hoffmeister, B. vollmer, T. Buddenberg, W. Song and A. kukoski: Ener. Proc., 1 (2009), 549.

4) C. S. Giggins and F. S. pettit: Oxid. Met., 14 (1980), 363.

5) M. R. Taylor, J. M. Calvert, D. G. Lees and D. B. Meadowcroft: Oxid. Met., 14 (1980), 499.

6) C. T. Fujii and R. A. Meussner: J. Electrochem. Soc., 114 (1967), 435.

7) G. H. Meier, K. Jung, N. Mu, N. M. Yanar, F. S. Prttit, J. P. Abellan, T. Olszewski, L. N. Hierro, W. J. Quadakkers and G. R. Holcomb: Oxid. Met., 74 (2010), 319.

8) F. Rouillard: Oxid. Met., 77 (2012), 27.

9) F. Rouillard: Oxid. Met., 77 (2012), 57.

10) I. Wolf, H. J. Grabke and P. Schmidt: Oxid. Met., 29 (1988), 289.

11) T. Gheno, D. Monceau and D. Young: Corros. Sci., 64 (2012), 222.

12) M. Small and E. Ryba: Metall. Mater. Trans. A, 12 (1981), 1389.

13) C. Wagner: Z. Elektrochem., 63 (1959), 772.

14) D. J. Young: High Temperature Oxidation and Corrosion of Metals, Elsevier, Oxford, (2008), 397.

15) K. Tapasa, A. V. Brashev, D. J. Bacon and Yu. N. Osetsky: Acta Mater., 55 (2007), 1 